\title{
Linked Gopher and World-Wide Web services for the American Psychological Society and Hanover College Psychology Department
}

\author{
JOHN H. KRANTZ \\ Hanover College, Hanover, Indiana
}

\begin{abstract}
The Internet is a vast and unorganized collection of information, making it difficult to find desired information. This paper describes the World-Wide Web (WWW) pages and Gopher directories designed to provide easy access to psychological resources set up by both the American Psychological Society (APS) and a college psychology department. The types of resources found at these sites include links to APS job listings, electronic journals, and psychology departments with Internet directories of information. One particular resource that is highlighted concerns the development of WWW tutorials in sensation and perception. These tutorials are offered as examples of how the WWW can be used to supplement texts and classroom instruction.
\end{abstract}

There is an increasing wealth of information on the Internet. With that wealth comes the difficulty of finding relevant information. Nowhere on the Internet is there a complete index of information that allows a user easily to find a particular file, program, or image (Allan \& Kostenbader, 1995). This problem is particularly acute for people who do not feel confident using computers. The phrase "I'm computer illiterate" has become a way of saying that one is not skilled enough to use the Internet, or that one might even "break" the Internet. It takes time to search and learn the Internet, perhaps more time than the typical professor or student has available. In an attempt to provide services that will enhance their use of the Internet, I began the development of a set of WorldWide Web (WWW) pages and Gopher directories at the request of the American Psychological Society (APS) and for the psychology department at my institution (Hanover College).

Before describing these Internet services, it is important to distinguish between the WWW and Gopher and to understand the reasons I have chosen to develop both in parallel. As can be seen in Levy's (1995) overview of the WWW, the WWW is a hypertext-based system with integrated graphics. For example, the top portion of the APS home page (Figure 1) includes a version of the APS's symbol and a paragraph that describes the page. There can even be instructions included in the page. Any form of image can be used as an illustration and embedded in the document. All of these features add to the readability and the quality of the information transfer possible through the WWW. However, information takes bandwidth, the technical term that refers to the speed at which

Correspondence should be addressed to J. H. Krantz, Psychology Department, Hanover College, P.O. Box 108, Hanover, IN 47243-0108.

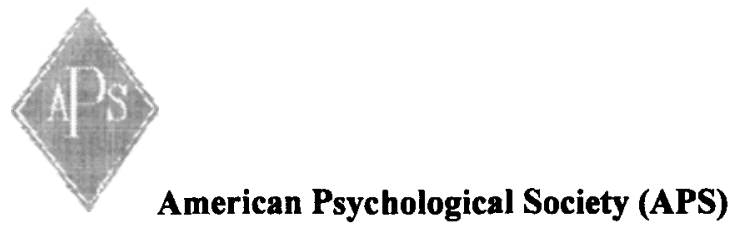

Jump to contents!

Welcome to the American Psychological Society (APS) http/gopher service. The files and directories are available for your use. Enjoy. If you have any problems or suggestions do not hesitate to contact me.

One thing that we are interested in doing is collecting a set of hypertext documents of the posters and presentations of the last conference. If you develop a hypertext document of your poster contact me at krantzj@hanover.edu and I will set up a new page with links to these documents so that your work will be available to the internet.

Figure 1. The appearance of the home page for the APS WWW service when downloaded via a WWW browser such as Mosaic.

information can be transmitted over an Internet connection. The more the information or the larger the file, the longer transmission will take. Thus, if the WWW page has lots of graphics, it can take a long time (sometimes many minutes) to transmit. This problem becomes severe for slow links, such as those over modems.

Gopher, on the other hand, is a set of directory listings. Figure 2 shows the main directory for the APS Gopher service. The user sees simply the titles of the directory items, with no explanation or embedded graphics. These titles may be links to remote sites, subdirectories, pictures, programs, or any other type of item that can be transmitted over the Internet. Most Gopher clients (the software that accesses Gopher information) will give some indication of the type of item that a directory entry comprises. In Figure 2, for example, $\{\mathrm{F}\}$ stands for a text 
\{F\} Welcome and what you can find here.

(S) Search all APS Menu Titles

\{D\} American Psychological Society General Information

\{F\} Memo to APS Board: Congressional Appropriations Update

(D) Selected Articles from the APS_Observer_.

\{D\} Abstracts from APS Conventions

\{D \} Research Related Information and Links

(D) Graduate Student Information

(D) Software Archive

(D) Electronic Journals and Periodicals

\{F\} Professional Psychology Related Listerv and Usenet Groups

\{F\} Neurosciences Discussion Groups; S. Bonario, S. Cormicle;

\{D\} APS _Employment Bulletin

\{D\} Job Search Services and Job Listings on the Internet

Figure 2. The appearance of the main directory of the APS Gopher service.

file and $\{D\}$ stands for another directory. The latter can be either on the same Gopher server or on any other Gopher server. Thus, Gopher presents information more cryptically than the WWW, and this may make it harder for the user to understand. However, the Gopher has one great advantage over the WWW: The Gopher system requires relatively low bandwidth, which means that transmission at great distances is much faster than it is for the WWW. In running both services, I have found that some people prefer the Gopher service and others the WWW service. As a result, I have decided to maintain both types of services, and to allow the user to choose between the two alternatives.

\section{THE APS SERVICE}

The APS WWW and Gopher service both contain virtually the same information, although the WWW pages allow access to information that Gopher clients do not handle (APS Resources, 1994). The APS WWW home page can be reached with any WWW browser (e.g., Mosaic or Netscape) via the URL (uniform resource locator) http://psych.hanover.edu/aps/. A URL is, in essence, the address over the Internet for any piece of information written in a format that WWW clients can read. See Chu, Walter, and Palya (1995) for more complete information on URLs.

The APS WWW organizes its information into the following categories:

- general information about the society, including membership information, articles from the APS Observer, and the poster abstracts from the last APS convention

- links to information for teachers of psychology, including links to a site in England (the CTI Centre in Psychology) with copious information about computer software resources useful for teaching psychology

- information for researchers, including links to the National Science Foundation and National Institutes of Health
- links for graduate students, including a link to the PSYCHGRAD Project, an Internet service for graduate students complete with an ongoing network discussion and even its own refereed electronic journal

- links to electronic journals

- links to other psychology departments that have information on the Internet

- links to job listings available on the Internet, including the APS Observer Employment Bulletin, which is searchable, so that one can find, for example, job listings for developmental psychologists by simply entering the word "developmental" and then getting a listing of all job advertisements for a developmental psychologist

- links to other lists of psychological resources

The emphasis of the APS page is on academic psychology.

\section{THE HANOVER COLLEGE PSYCHOLOGY DEPARTMENT'S SERVICE}

The Hanover Psychology Department WWW and Gopher services are focused on the students at the college and on increasing their use of the Internet. The Hanover psychology home page can be found at the URL http://psych.hanover.edu/. Since the aim of the department's home page is to assist the department's students, the largest section of the home page is the section on student information. In this section, we have a link into the student handbook (Terry \& Krantz, 1994), an ideal type of document for the hypertext environment. A handbook is not the type of reading material that is intended to be read straight through; rather, for such a document, the student wants access to specific sections, and their requirements will vary over time and across situations. Hypertext works well in this type of application because the student simply accesses the table of contents and clicks on the appropriate section to access that section of the document directly. In a printed handbook, the student must first find the contents, then look up the page number of the section containing the required information, and finally search for that page. There is no direct access in a printed document. Other resources for students in this section include information on various student societies and a link to the PSYCHGRAD Project.

The department has also begun placing information for its courses on the Internet for the students. This information includes syllabi and links to sites useful for specific courses. The information is organized by course number and title. An example is a link to a collection of single-image random-dot stereograms for the sensation and perception course.

In addition, the department's Internet services contain links relevant to applying to graduate school or searching for a job. Hanover's Career Center has a WWW page, and students can access it via the department's WWW 
page. We also have lists of questions asked in graduateschool interviews of our students that other students can review in preparation for their interviews.

\section{THE TYPES OF RESOURCES COMMON TO BOTH SERVICES}

Several types of information are available via both the APS home page and the department's home page. These resources are placed in their own pages to minimize the redundancy of information and to keep the main pages at a reasonable size and the speed of transmission as high as possible. For example, users can access a relatively complete list of electronic journals from either page. These journals include more strictly psychology-oriented journals, including Psycoloquy, a refereed journal sponsored by the American Psychological Association. This journal has a unique format: a lead article is submitted on a topic, and then other authors can submit for review articles that comment on this lead article. There are also links to interdisciplinary journals such as Psyche, which deals with the topic of consciousness from a wide range of disciplines. In addition, traditional journals that place contents or abstracts on the Internet are accessible from these pages. The Journal of the Experimental Analysis of Behavior, for example, recently placed 35 years of abstracts on the WWW. Along with journals, the proceedings from a few recent conventions are available on this list, most of which are searchable by keywords. In the case of the APS, the proceedings are posted before the conventions, enabling registrants conveniently to identify papers of interest to them before they attend.

Another type of resource under development is a list of psychology departments on the Internet. This list, which is relatively short but growing rapidly, can be useful in a number of ways. For example, students interested in graduate schools can find out a great deal of information about a department from its Internet directories. Many departments have course listings, requirements, course syllabi, and even faculty research on the network. Faculty interested in curricular development can examine other schools' curriculi to serve as a base of comparison for their own curriculum. This list of psychology departments can also serve as another way in which to gain access to research information, since many faculties are posting their research on the network.

\section{PSYCHOLOGICAL TUTORIALS}

The final topic to be discussed concerns the tutorials in the area of sensation and perception that I have been developing on the WWW for student use. Because it is an interactive medium, the WWW is wonderful for developing tutorials. It is not merely a means of accessing information or documents, as Gopher is-it allows documents to be designed that respond in a manner that provides feedback, the basis of an interactive medium. For example, a WWW tutorial can query students and offer a choice of responses (in advanced versions of the
WWW, students can even type their responses). On the basis of their responses, the tutorial can give the students feedback. In addition, integrated graphics allow the creator of tutorials to illustrate complex concepts in a way that is difficult to do in many other media. The creator can even use animations, movies, or sounds to further enhance the learning experience. In this section, I will describe two of the three tutorials that I have begun as an example of what is possible. Briefly, the third tutorial illustrates Fourier analysis, a mathematical procedure that allows any complex pattern to be described by a set of fundamental sine waves. This mathematical procedure has been a helpful analogy for understanding both vision and audition. The tutorial uses many of the concepts discussed in the following descriptions of the other two tutorials.

\section{Receptive Fields Tutorial}

The concept of receptive fields seems to be one that causes students to struggle. One source of this conceptual difficulty may be that in vision, the analogy between the eye and the camera breaks down, as there are no lateral interactions in the camera (Coren, Ward, \& Enns, 1993). Thus, it seemed appropriate to develop a tutorial to assist students with this difficult concept.

The receptive fields tutorial also demonstrates one of the ways in which to develop interactive learning experiences on the WWW. One of the aspects of the receptive fields concept that seems to plague students concerns the location of the receptive field-that is, whether it is with the stimulus, with the sensory receptors, or in the cell being recorded. To help students with this concept, the tutorial defines and describes a receptive field and then shows an illustration that diagrams how an experiment measuring a receptive field is conducted (Figure 3). The illustration was created using a paint program (in this case, Paintbrush that comes with Windows). To create the lens in the eye and the brain, circles and ellipses from the toolbox menu of Paintbrush were overlapped, and the unnecessary parts erased. The lens in the eye is composed of parts of two circles with different radii, and the brain is composed of parts of five different circles. Many different figures can be created using the stock graphical tools that come in most standard paint programs, so that the quality of the illustration does not depend on the ability to draw well.

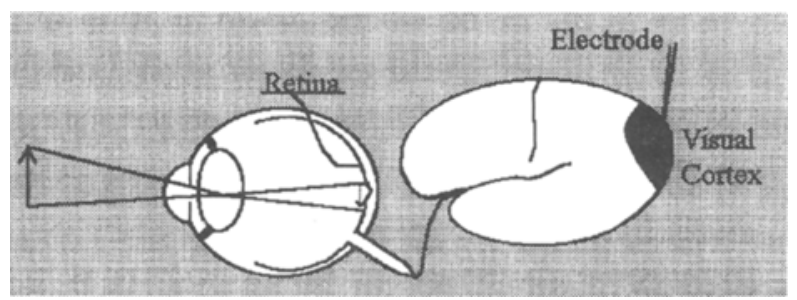

Figure 3. A figure from the receptive fields tutorial (Krantz, 1994), depicting an experiment mapping a receptive field. (From Receptive Fields Tutorial [on-line], by J. H. Krantz, 1994. Copyright 1994 John H. Krantz. Reprinted with permission.) 
In this tutorial, the student is asked where the receptive field is found: with the stimulus, with the sensory surface (the retina), or in the brain where the cell is being recorded. It would be natural for the student to respond by using the mouse to point to the region where he or she thought that the receptive field was located and then, by clicking on that region, to receive appropriate feedback. With most WWW servers, it is possible to have students make responses directly to graphical images and to give feedback that depends on the place in the image where the student made the response. This technique, called mapping, requires an additional piece of software that comes with the server software.

While the specifics vary depending on the type of WWW server, the basic mapping steps are probably fairly similar across most WWW servers. Once the image is completed, the following four fairly simple steps are involved: (1) The regions of the image that will cause different responses need to be defined. I use an image-editing program that will indicate the location of a region being block-marked to be cut or copied. The program is readily available on the Internet, and is freeware; in fact, several programs will provide this information. I record those regions, but decline to cut or copy the region. (2) A small text file, called a map file, is created. On separate lines in the file, I indicate the region of the image and where the server is to go to get the next document if the student clicks in that region. In this example, if the student clicks on the retina, the server will be directed to a WWW page that contains a modification of Figure 3 highlighting the region around the retina, to provide the student with feedback about his or her selection. The student is told that his or her choice is correct, and is given a brief explanation as to why that choice is correct, as well as a reference. (3) The program that will read the map file needs to be told that this file exists. This step is done by editing a configuration file, placing a line in it to indicate where it will find the map file when a map figure is clicked on. (4) When the image is included in the program, the command ISMAP is added to the statements for including the image (Chu, et al., 1995). Depending on the complexity of the number of sites that will be responded to in an image, these steps take under 15 minutes.

Maps also allow the server to respond if the student clicks outside any of the defined regions. In the case of the receptive field tutorial, the student is given a WWW page with the title "Not."

\section{Vision and Art Tutorial}

One of the nice features of teaching a course in sensation and perception concerns all the various ways in which the principles of sensation and perception have been applied, sometimes centuries in advance of the scientific study of the concepts. One way in which many of the concepts of sensation and perception, especially depth perception, have been applied is in art, a nice way to illustrate many concepts of vision. Artists who have painted have had to deal with a problem similar to that dealt with by the brain: How can three-dimensional in- formation be represented on a two-dimensional surface? For the brain, the problem lies in extracting a world with depth from a flat retina; for the painter, the problem consists of depicting the depth relationships of the world on a flat canvas.

This tutorial is an attempt to help students see the application of visual knowledge in the world around them. The major portion of the tutorial is concerned with depth information. Each page presents an illustration of a concept (e.g., the depth cue of interposition that is clearly shown by two overlapping squares). The concept is then discussed, and a scanned painting or drawing is shown to illustrate how the concept has been applied in art. For example, in the page on interposition, a painting that depicts several figures overlapping each other-Botticelli's Madonna of the Magnificat-is shown, and there is a brief discussion of how the overlap plays a role in the viewer's perception of depth. The images that are integrated into WWW pages are generally not as good as those that can be viewed on a graphics viewer, so the student can click on the image in the text and view a larger copy of the picture. The quality of the image still depends on the quality of the monitor that the student is using. In addition to topics relating to depth perception, there are topics on figure-ground perception, impossible figures (figures that can be depicted in a two-dimensional surface but that are impossible in a three-dimensional space), and spatial integration, which is illustrated by pointillist paintings, in which the image is created by small dabs of paint placed next to each other (de la Croix, Tansey, \& Kirkpatrick, 1991).

This tutorial can either be followed in a sequential order by clicking arrows at the bottom of the page or accessed in a random order. On the introductory page of the tutorial, there is a map which contains each of the illustrations for each of the pages that have so far been written, as well as the title of the page overlapping the figure. By clicking on the illustration, the student will go directly to that page. Thus, students can move through the tutorial in any order they choose.

\section{CONCLUSION}

The Internet is a vast and confusing collection of information and resources. The WWW is also a vast and almost equally confusing collection of resources distributed across the Internet (Levy, 1995). The pages developed for both the APS and Hanover College Psychology Department illustrate how these resources can be collected for specific needs to make the world of the Internet less confusing. I have used these resources in my classes, requiring students to find research articles off the Internet, for example. Such an assignment would be nearly impossible if the students had to find the location of the electronic journals on their own. These pages are not a complete collection, but they are growing continuously as resources on the Internet increase.

The tutorials represent another way in which the WWW can be used for educational purposes. These tutorials can 
supplement the instruction provided in the classroom and in the textbook. Moreover, the local teacher is not required to develop a complete set of tutorials. Since the tutorials are available worldwide, as the number of tutorials increases, the local teacher merely collects a list of them on a local page and the student selects the appropriate tutorial. Such a collection of tutorials may circumvent one problem that is endemic to textbooks written by one or a few authors: By being responsible for a wide range of topics, the author is bound to make mistakes, especially outside his or her area of expertise; if we develop tutorials only in our area of expertise and use tutorials developed by others in their area of expertise, the quality of information presented to students should improve.

\section{REFERENCES}

ALlan, R. W., \& KosTENBaDER, P. S. (1995). Information on the Internet: How selective should we be? Behavior Research Methods, Instruments, \& Computers, 27, 198-199.
APS RESOURCES ARE NOW ON INTERNET (1994, July/August). APS Observer, 7, 6 .

Chu, J. Y. M., Palya, W. L., \& Walter, D. E. (1995). Creating a hypertext markup language for an information server. Behavior Research Methods, Instruments, \& Computers, 27, 200-205.

COREN, S., WARD, L. M., \& ENNs, J. T. (1993). Sensation and perception (4th ed). New York: Harcourt Brace.

DE la CROIX, H., TANSEY, R. G., \& KirKPATRICK, D. (1991). Gardner's art through the ages (9th ed). New York: Harcourt, Brace, Jovanovich.

KRANTZ, J. H. (1994). Receptive fields tutorial [On-line] Available Internet. URL: http://psych.hanover.edu./krantz/receptive/

LEvY, C. M. (1995). Mosaic and the information superhighway: A virtual tiger in your tank. Behavior Research Methods, Instruments, \& Computers, 27, 187-192.

TerRY, R. L., \& KRANrz, J. H. (1994, June). A psychology student handbook. First Annual APS Institute on the Teaching of Psychology, Washington, DC.

(Manuscript received November 29, 1994; revision accepted for publication January 20,1995 .) 